\title{
Are psychiatry attachments in developing countries for the British trainee useful?
}

\author{
Ruth McCutcheon
}

\begin{abstract}
Experience of poschiatry in a developing country is not cenerally regarded as pertinent to the training of the Brtitsh poschiatist. In this article I draw on my own experience of a poychiatic attachment in india to argue that such experience can be useful and relevant for Bittish poychiatiy trainees, and that II should be encouraged.
\end{abstract}

There is a general acceptance that trainee psychiatrists from developing countries can enhance their training by working for a period in a developed country. This assumption is widely held even though it has been pointed out that the training they recelve may not be tailored specifically to their needs and may not equip them with the psychiatric, teaching, management and service development skills likely to be required of them should they return to psychiatric practice in their own country (Holden, 1989; Mbwambo et al, 1992). The general acceptance of the value of overseas training does not apply to the reverse situation, i.e. to a Western trainee working for a period in a developing country. In a recent survey by Haigh \& Weaver (1993) Fellows and new Members of the Royal College of Psychiatrists were asked to grade 27 factors of possible relevance to senior registrar appointments committees for degree of importance. Overseas experience came 25th, only ' $O$ ' and ' $A$ ' levels' and 'schools attended' scoring less.

\section{What can the British traince gain from work overseas?}

During my registrar training I spent a six month attachment at a large psychiatric institute in southern India. I found the experience valuable and feel that this sort of attachment would be relevant for any psychiatrist who intends to practise in a multi-cultural country such as Britain.
The following are some of the ways in which my short time observing psychiatry in India benefited me. They could apply equally to work in any developing country.

\section{Sensitisation to cultural issues}

Being a member of the current dominant (Western) culture can lead to the notion that Western culture is the norm from which all other cultures somehow deviate. Exposure to a society where many of one's basic assumptions are simply not shared by others helps to sensitise one to one's own ethnocentric view point and begin to see both one's own culture and other cultures more clearly. Indian beliefs about impermanence and fate, the relative unimportance of the individual and the use of ritual and symbolism in everyday life made me acutely aware of certain Western beliefs, for example, the importance of material progress, the individual's ability and duty to mould his/her own destiny and mind/body dualism. It also became clear when observing psychiatric practice in India that Western beliefs have influenced psychiatry to such an extent that its concepts are not always useful when applied to mental distress occurring in people of non-Western backgrounds. Real awareness of these issues is of crucial help to any psychiatrist treating patients of a different cultural background to him or herself.

\section{Widening of psychiatric experience}

Certain types and presentations of mental disorders which are rarely seen in Britain are much commoner in other cultures. For example, I saw cases of depression presenting primarily with somatic symptoms, conversion hysteria, and untreated cases of congenital hypothyroidism in children aged 
four or five presenting for the first time. I also observed psychiatry being practised in a rural community setting with few resources.

\section{Experience of the development of psychiatric services}

Working in a country where psychiatric services are still at a fairly early stage of development one can observe the issues and problems surrounding the planning and implementing of services; for example. assessment and prioritisation of population needs, budget limitations, rural v. urban services, training of staff and utilisation of primary health care services.

\section{Experience of being an outsider}

For any white British psychiatrist, time spent living in a country where one is a different colour from everyone else and on the wrong side of the language barrier can provide insight into the problems faced by immigrants to Britain, some of whom we will meet and treat as patients.

\section{Empathy for overseas doctors on their arrival in Britain}

Working abroad equips one with more understanding of the potential personal and work problems facing overseas doctors on their arrival in Britain, and gives one a much clearer understanding of their training needs.

I suggest that for the above reasons overseas work experience in developing countries should no longer be seen as largely irrelevant for the British psychiatrist but, on the contrary, should be recognised both as an important component of overall training and as a valuable asset to psychiatric practice in this country. The host country has perhaps less to gain, particularly where the trainee is not fluent in the local language. However, there could be an element of service input and those trainees with sub-speciality experience could give valuable teaching to mental health professionals in countries where psychiatric services are less well developed. A two-way movement of doctors between developed and developing countries could help promote research links, exchange of ideas and trans-cultural research projects.
Interested trainees should be actively encouraged to spend time working abroad, preferably at senior registrar level and for a period of not less than two years. Language tuition could be given in advance of departure. Funding would, of course, be a problem as would the issue of recognition of overseas work for higher training purposes. Placements could be based on exchange schemes, such as the one organised by Charing Cross Psychiatric Training Scheme and the National University Hospital in Singapore (Robertson et al, 1992) or on secondments which could be organised perhaps by the Overseas Doctors Training Scheme as suggested by Piachaud (1992), or by the World Health Organisation, Overseas Doctors Association or Commonwealth Secretariat who have apparently expressed an interest in such schemes (Guinness \& Persaud, 1992).

In 1990 the Royal College showed its concern about issues of racial discrimination, prejudice and lack of cultural awareness and their effects on the relationships between psychiatrists and ethnic-minority groups in this country. It issued a statement, making a list of 26 recommendations for the improvement of psychiatric practice and training in British multi-ethnic society (Royal College of Psychiatrists, 1990). Perhaps encouragement of overseas experience for British psychiatrists would be a worthwhile addition to the list.

\section{References}

Guinness, E. A. \& PERsaud, R. (1992) Training and support for research in developing countries. (Letter). Psychiatric Bulletin, 16, 726-727.

HNGH, R. \& WEAVER, M. (1993) Rumour, myth and reality at SR interviews. Psychiatric Bullettn, 17, 541-543.

HOLDEN, N. L. (1989) Training in psychiatry in less developed countries. Psychiatric Bulletin, 13, 558-560.

MWAMBO. J.. APPLEBY, L. \& GATER, R. (1992) The training of psychiatrists for the developing world. Psychiatric Bulletin, 16, 352-354.

PIACHAUD. J. (1992) Overseas doctors-training ethos. (Letter). Psychiatric Bulletin, 16, 666.

ROBERTSON, J. R. HALSTEAD, S., TAN, T. \& LAWRENCE J. (1992) Psychiatric training. Singapore. Psychiatric Bulletin, 16. 36-38.

Royal Coulege of Psychiatrusts (1990) Statement by Council on Psychiatric Practice and training in British mult-ethnic society. Psychiatric Bulletin, 14, 432-437.

Ruth McCutcheon, Senior Registrar in General Psychiatry, Fazakerley Hospital, Liverpool L9 7AL 